\title{
Fishy foreign objects
}

CrossMark

$\leftarrow$ click for updates

\section{Case report}

A 67-year-old female was admitted to hospital with systemic symptoms and shortness of breath. Over the previous 3 months, the patient had noticed shortness of breath on exertion and her exercise tolerance had decreased from several miles to half a mile. She had also developed intermittent pyrexia, lethargy and night sweats. There was a previous history of microscopic colitis, which was well controlled on azathioprine $100 \mathrm{mg}$ b.i.d. In addition, the patient was an exsmoker of 10 years with a 20-pack-year history. She had no tuberculosis contacts and had not recently travelled outside Europe.

On admission, she had an intermittent lowgrade pyrexia, a pulse of 90 beats. $\mathrm{min}^{-1}$ and blood pressure of $120 / 70 \mathrm{mmHg}$. There was decreased air entry and percussion note at the right base. Chest radiography was performed and the results are shown in figure 1.

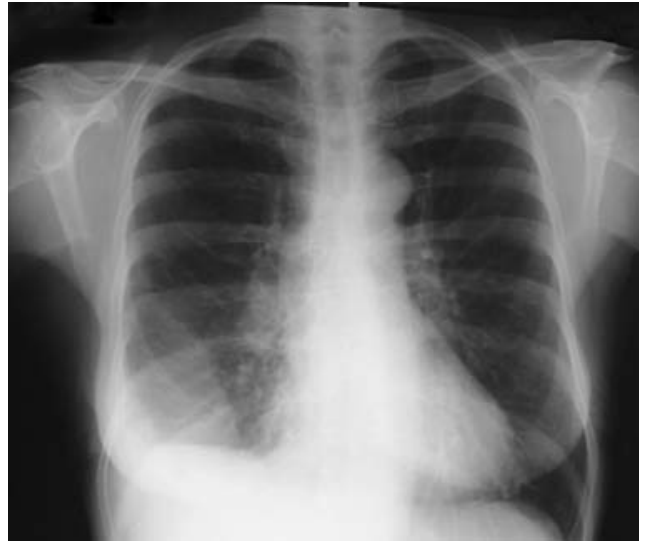

H. Bakere ${ }^{1}$

G. MacGann ${ }^{2}$

P. Rajesh ${ }^{3}$

I. Mortimore 1

Depts of ${ }^{1}$ Respiratory Medicine and ${ }^{2}$ Radiology, Cheltenham General Hospital, Cheltenham, and ${ }^{3}$ Dept of Thoracic Surgery, Hartlands Hospital, Birmingham, UK.

\section{Figure 1}

Chest radiograph.

\section{Task 1}

Interpret the chest radiograph.

\section{Correspondence:}

\section{H. Bakere}

Dept of Respiratory Medicine Cheltenham General Hospital Cheltenham

GL53 7AN

UK

Fax: 441872275031

E-mail:hbakere@yahoo.com 


\section{Answer 1}

The chest radiograph reveals a radio-opaque area with a meniscus at the right base suggestive of a fluid collection.

\section{Investigations}

Ultrasound demonstrated a right posterolateral lower pleural cavity empyema. Pus was aspirated during this procedure and an $8 \mathrm{~F}$ drain was inserted. The aspirate was negative for acid-fast bacilli, but did grow two types of Streptococcus, Gemella spp. and Streptococcus mitis. The patient was given ceftriaxone. Treatment with azathioprine was temporarily stopped. Subsequently, a computed tomography (CT) scan of the thorax was performed.

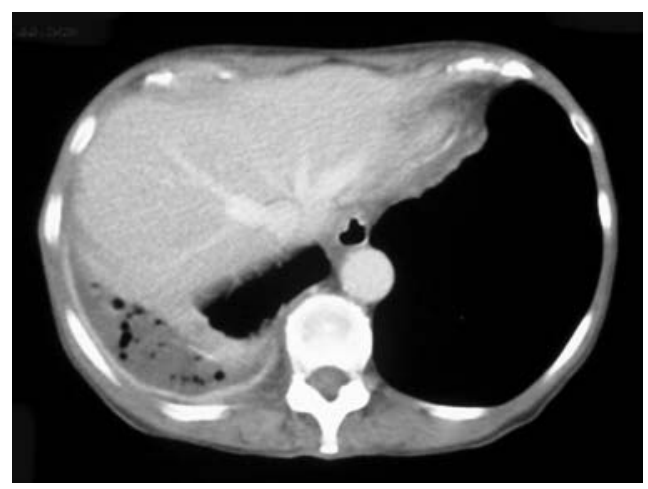

Figure 2

CT scan of the thorax.

\section{Task 2}

Interpret the CT findings.

\section{Answer 2}

The CT scan shows an elliptical fluid collection within the peripheral posterolateral aspect of the right hemithorax. The pigtail drain can be seen in situ. A thin 3-cm foreign body is also visible.

Drain output remained poor, and there was no improvement following an injection of 25,000 units of streptokinase into the drain.

\section{Task 3}

How would you progress with the management of this patient? 


\section{Answer 3}

The patient has a non-resolving empyema, possibly containing a foreign body, which has failed to resolve with simple drainage. Thus, referral to thoracic surgery for possible surgical intervention is required.

The patient was referred for surgery. She underwent a rigid bronchoscopy, right thoracotomy and a decortication. A fish bone was retrieved from the bottom of the pleural cavity (figure 3). She was discharged on her 4th postoperative day and made a complete recovery.

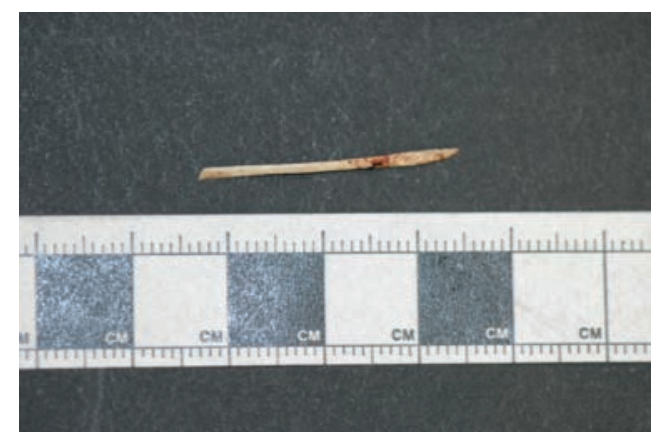

Figure 3

Fishbone recovered at operation.

Careful review of the patient's dietary history revealed that she ate a considerable number and variety of sea fish, but did not recall, on any occasion, a bone sticking in her throat or any chest pain.

\section{Discussion}

The case presented here describes a 67-year-old patient who developed a pleural empyema. Presumably, this occurred as a consequence of a clinically silent oesophageal perforation by a fish bone a number of months before presentation, when the patient was immunosuppressed with azathioprine. The radiological and surgical evidence showed that the oesophageal perforation had healed completely by the time of the patient's presentation. Following the treatment of the empyema, the patient made a full recovery.

It is interesting to note that the CT scan demonstrated a radio-opaque linear foreign body that ultimately proved to be a fish bone. It is known that only certain types of fish bones are easily visible on plain radiography, generally the denser bones of those that inhabit deeper waters, such as cod, haddock and sole [1]. CT with greater contrast sensitivity can demonstrate more types of bone or foreign bodies when compared with plain film. There is at least one previous report of $\mathrm{CT}$ imaging identifying a fish bone within an empyema [2].

Oesophageal perforation accounts for $5 \%$ of cases of pleural empyema [3]. In cases of oesophageal perforation, it is felt that $50-75 \%$ have a normal oesophagus [4]. Classically, oesophageal perforation presents acutely with retro-sternal chest pain, and sepsis due to contamination of the mediastinum and thoracic cavity by the gastro-oesophageal contents. The reported mortality ranges 9-32\% [5].

Fish bones are a known cause of oesophageal injury. A recent Japanese case report described a 65-year-old patient with an endoscopically proven oesophageal injury that healed spontaneously after 4 weeks [6].

It is presumed that the patient presented here had an oesophageal perforation from a fish bone, which healed spontaneously. Her presentation a number of months later was a result of the chronic empyema that had developed. The patient appeared to have survived the acute phase without any symptoms or medical intervention.

Case reports of oesophageal perforation with fish bones indicate that some patients do present acutely unwell with septic shock, mediastinitis and even gas gangrene [6-8]. However, the current patient followed a much more benign course, and a further case without signs of sepsis has also previously been recorded [2]. A possible hypothesis could be that, in some cases, the fish bone may penetrate the oesophagus, causing limited local injury with little chemical and biological contamination from the gastrointestinal tract. The fish bone could subsequently act as a focus of infection with gradual development of an empyema. 


\section{References}

1. Raby N, Berman L, Lacey G. Accident and Emergency Radiology. 1st Edn. Edinburgh, Saunders, 1999.

2. Solomonov A, Best $L A$, Goralnik $L$, Rubin AE, Yigla M. Pleural empyema: an unusual presentation of esophageal perforation. Respiration 1999; 66: 366-368.

3. Light RW. Para-pneumonic Effusions and Empyema. 3rd Edn. Baltimore, Williams and Wilkins, 1995.

4. Reeder LB, DeFillipi VJ, Ferguson MK. Current results of therapy for esophageal perforation. Am J Surg 1995; 169: 615-617.

5. Lam HC, Woo JK, van Hassel CA. Esophageal perforation and neck abscess from ingested foreign bodies: treatment and outcomes. Ear Nose Throat J 2003; 82: 786-784.

6. Saji N. A case oesophageal perforation with haematemesis and mediastinitis caused by a fishbone. Gastroentological Endoscopy 2004; 46: 912-914.

7. Turcot R, Gagnon RM, Joassin AM, Noel C, Delorme J, Loveland M. Anaerobic mediastinitis and septic shock secondary to esophageal perforation. Can J Surg 1979; 22: 382-384.

8. Endo S, Kobayashi A, Hasegawa T, Yamaguchi T, Murayama F, Sohara Y. Pleural gas gangrene secondary to esophageal injury by an ingested fish bone. Jpn J Thorac Cardiovasc Surg 2002; 50: 178-180. 